\section{Sorption phenomena of PCBs in environment}

\author{
MENG Qingyu, CHU Shaogang \& XU Xiaobai
}

Research Center for Eco-environmental Sciences, Chinese Academy of Sciences, Beijing 100085, China

Correspondence should be addressed to $\mathrm{Xu}$ Xiaobai (e-mail: xbxuac@bj.col.com.cn)

\begin{abstract}
The relationship between the properties of PCBs and the behavior of soil and sediment is reviewed. The sorption phenomena of PCBs in the environment are described with different models. The research progress on the sorption mechanisms is also discussed.
\end{abstract}

Keywords: PCBs, sorption, environmental transport.

Polychlorinated biphenyls (PCBs) are one group of the persistent organic pollutants (POPs), which contain so far 12 groups of chlorinated compounds. They can also be incorporated into dioxin-like compounds. As early as May 1995, the UNEP Board of Directors passed the 18/32 resolution to do appraisal of POPs. The global protocol of management on POPs will be formulated in 2000 , and the Chinese government will participate in the international cooperation.

The commercial production of PCBs began in 1930 . Industrial manufacturing of PCBs is based on the chlorination of biphenyl in the presence of suitable catalysis. Over one million tons of PCBs have been produced in industrialized countries. The organization for Economic Co-operation and Development (OCED) environmentally divided the use of PCBs into three categories, i.e. the completely closed system, nominally closed system and open-ended application. PCBs commercially produced began in 1965 in China, named $\mathrm{PCB}_{3}$ and $\mathrm{PCB}_{5}$. By the end of 1974, most of the factories stopped the production of PCBs and in the early 1980 s commercial production of PCBs was completely banned in China. Within this period of time, approximately $10^{7} \mathrm{~kg}$ PCBs were produced and most of the products, about 9000 tons, were used as dielectric fluid in electric capacitors, except that a small part $(1000 \mathrm{t})$ was used as additives in paints and have emitted into the environment. By now most of the electric capacitors containing PCBs have been worn out. Furthermore, some electric capacitors and transformers containing PCBs were imported into China without pre-notification from some developed countries from 1950 to 1970 or even later.

Although the commercial production of $\mathrm{PCBs}$ has been banned for almost two decades, improper disposal of the PCBs containing appliances will cause and has caused serious pollution in some areas. In addition, PCBs can also be as byproducts in industrial process such as chloranil and dicloran production. PCBs will emit into the environment when the chemicals are produced and used. It has been reported that PCBs can be converted to PCDD/Fs under the pyrolytic condition. This will cause serious results. $\mathrm{PCBs}$ entering the environment will go into the global cycling of materials and energy. They have even been found in the water, soil and organisms in Tibet.

Sorption is one of the most important transport processes of volatile organic compounds (VOCs) and synthetic organic compounds (SOCs) in the environment. The research of the sorption phenomena will benefit the study of POP's environmental behavior more intensively and extensively. The results will support the management of POPs in China.

\section{Basic properties of PCBs and their environmental behavior}

PCBs, which are widely used as commercial product, are chlorinated aromatic hydrocarbons. The chlorination of biphenyl can lead to the replacement of $1-10$ hydrogen atoms by chlorine $e^{[1,2]}$. Theoretically, PCBs include 209 congeners. The structure of PCBs is shown in scheme $1(1 \leqslant m+n \leqslant 10)$. The mobility of PCBs mixture decreases as the degree of chlorination increases and they appear from state of liquid to that of solid.

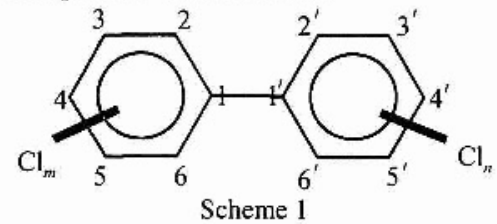

PCBs have a high degree of physical and chemical stability under normal conditions. They are very resistant to acid, base and oxidants. They are, in practice, fire resistant with rather high flash points. The liquid phase vapor pressures of PCBs at ambient temperature are not very high but the change of temperature will affect them significantly ${ }^{[1]}$. PCBs have low aqueous solubility and most of their values of $K_{\mathrm{OW}}$ are greater than $10^{4[3]}$.

PCBs are distributed ubiquitously in the environment ${ }^{[4]}$. Because of their low solubility and high value of $K_{\text {Ow }}$, their concentrations in the atmospheric and aquatic environment are very low. For example, it was reported that in America the concentration of PCBs in the atmosphere is normally $1-10 \mu \mathrm{g} / \mathrm{m}^{3}$, and that in the aquatic environment is less than $2 \mu \mathrm{g} / \mathrm{m}^{3}$. Nevertheless, the suspended particles in the water will accumulate PCBs. Some investigations show that the concentration of solid-combined PCBs is greater than $100 \mu \mathrm{g} / \mathrm{m}^{3}$ no matter whether in fresh water or in sea water ${ }^{[1]}$. Data reported recently mean that there is the same possibility that PCBs present in the surface water and in the ground water. This will be harmful to the water supply in industrial areas over a long period of time ${ }^{[2]}$.

The main routes of environmental pollution with PCBs are their release into the atmosphere, leakage and 
improper disposal of them in industry. Other ways by which PCBs dispersed into the environment include combustion of industrial and urban wastes, storage and bury of wastes in landfill sites. Although the amount emitted by those ways is much less, they can also make PCBs go into food chains ${ }^{[4]}$. PCBs may volatilize into the atmosphere during their use and disposal and then they may come back to land and aquatic environment by dry or precipitation deposition. In most areas of North America, PCBs in the soil are mainly originated from the atmosphere. There are $1000-2000 \mathrm{t}$ PCBs deposited on the soil from the atmosphere, especially in urban areas. Other than deposition, PCBs in soil derive from the use of sewage sludge as a fertilizer, leaching from landfill sites and the use of pesticides containing PCBs. PCBs enter water mainly from discharge points of industrial and urban wastes into rivers, lakes and ocean. Sewage treatment can only remove the solid-combined PCBs, but it cannot remove the dissolved parts. When discharged into open water, that part of PCBs will concentrate on solved particles and then sink into the sediment with different rates according to the particle size and accumulate there. The sinking rate of PCBs from the surface to deeper layers in the open ocean is relatively slow in tropical waters than in high-latitude waters ${ }^{[5]}$. With the use of PCBs decreasing sharply, PCBs in the sediment will become the main source of food chains ${ }^{[1,4]}$.

PCBs in water cannot be hydrolyzed and their retention period in water is very short because of their high hydrophobicity and chemical stability. PCBs cannot be decomposed chemically other than by photolysis in the environment. And bioavailability can do some work in the decomposition of PCBs. When PCBs go into food chains, the congeners with low chlorination will be biodegraded stepwise. Congeners with a low degree of chlorination can be totally decomposed by this way ${ }^{[1,2,4]}$.

As early as the 1930 s, cases of poisoning were reported among men engaged in their PCBs manufacture. The nature of this occupational disease was characterized by a skin affection with acneiform eruptions. Occasionally the liver was involved, in some cases causing fatal consequences. PCBs can stimulate the enzyme activity in microsome. And the function of the chemicals that can be activated by microsome enzyme will be strengthened while the function of those chemicals detoxified by microsome enzyme will be weakened. PCBs are mainly metabolized in the liver in mammal. Other than potential carcinogenicity PCBs are known as teratogenic agent. And they are toxic to laves and zygotes ${ }^{[2,4,6,7]}$. In 1972, the production and use of PCBs were banned by law in Switzerland. In UK and USA, only the congeners with low degree of chlorination can be sold and used as dielectric in closed systems ${ }^{[4]}$. After that, many countries restricted the sale of PCBs. PCBs were also listed as priority pollutants by USEPA since the $1970 \mathrm{~s}^{[8,9]}$.
In recent years, with the application of advanced analytical methods, such as MDGC, GC/HPLC and GC/MS/MS, it is possible to separate and analyze all the 209 congeners and this will favor the research on transport and transformation processes of PCBs in the environment $^{[10-14]}$.

\section{Environmental sorption behavior of $\mathrm{PCBs}$}

( i ) The importance and necessity of the study on the role of sorption on the distribution of PCBs in environmental system. Sorption behavior plays a significant role in numerous natural processes ${ }^{[15]}$. Direct sorption from the gas phase to solid surface may be a significant exchange pathway for VOCs and SOCs between atmosphere, soils and vegetation. An important characteristic of sediments is the high concentration and the vast variety of natural surfaces that are in contact with dissolved solutes. Due to this high solid-to-water ratio, dissolved pollutants may be significantly retained and accumulated in the subsurface, even if the interactions with the solid matrix be rather weak. In soil, if HOCs combine with humus, their environmental behavior will change. In addition, it is generally accepted that freely-dissolved hydrophobic pollutants are more bioavailable than those bound to particles $^{[6-18]}$.

The sorption of organic pollutants from gas or liquid to solid surface appears in different mechanisms from physical adsorption to chemical sorption. The degree of sorption will not only affect the transport of organic pollutants in the environment, but also have an effect on their photolysis, hydrolysis, volatilization and biodegradation $^{[19]}$

Hence, to understand the distribution status of toxic pollutants and quantitative description of their exchanging flux from water to sediment it is important to simulate the sorption process of pollutants, build up the mechanism model of sorption/desorption and determine the energy balance and rate related to sorption ${ }^{[15,19,20]}$.

Because of PCBs' high hydrophobicity, their environmental behavior will significantly depend on sorption phenomena ${ }^{[21]}$. PCBs in the aquatic environment are mainly adsorbed on the sediment and suspended particles and then transported to areas far away from the source of pollution. Due to the combination of PCBs, the concentration of PCBs in the sediment near estuary can be as high as $2000-5000 \mu \mathrm{g} / \mathrm{kg}^{[2,5]}$. In highly polluted waters, the concentration of PCBs will be several times higher than their solubility. This is also caused by the interaction between PCBs and solid particles in water ${ }^{[1,4]}$.

Therefore, the investigation of the mechanisms of sorption and desorption will be helpful to revealing the harmful effect of PCBs on human beings and environment.

(ii ) Sorption process, equilibrium and kinetic reaction rate model 
(1) Sorption process. Sorption is a general term describing that a sorbate molecule interacts with sorbent phase ${ }^{[20]}$. According to the degree of interaction between sorbate and sorbent, two broad categories of sorption phenomena, adsorption and absorption, can be differentiated. Adsorption processes occur at the solid solution interface, and in the absorption processes the solute penetrates the bulk of the sorbing phase $\mathrm{s}^{[8,15,16]}$. Sorption results from a variety of different types of attractive forces between sobate molecules, sobent molecules and Lewis acid-base interactions ${ }^{[16]}$. According to the three types of attractive forces, three types of adsorption, the chemical, the electrostatic, and the physical, can be distinguished.

Physical sorption results from the action of van der Waals' forces. As for HOCs, the combined effect is often called hydrophobile bonding. The energy driving hydrophobic molecules out of solution can be explained according to the structure of water. The structural associations of $\mathrm{H}_{2} \mathrm{O}$ molecules in liquid water exist in two kinds. One is crystalline ice type and the other is agglomeration type. A non-polar molecule can be held in solution by an arrangement of the ice-like crystals around the solute and the reaction is generally exothermic. In the process, the favorable enthalpy and unfavorable entropy happen. If the system can achieve a state that is thermodynamically favorable to precipitation, solute molecules can be driven out from solution. The intensity of the interaction can be measured by heat of adsorption. Chemical sorption can often be identified by the type of isotherm that suggests high partition at low solute concentrations. Actual sorption processes probably involve various degrees of all types of interactions, but one type often predominates ${ }^{[22]}$. The relationship between the types of sorption and different types of attractive forces are listed in table 1.

Table 1 Types of sorption and different types of attractive forces

\begin{tabular}{clc}
\hline Type of adsorption & Type of interaction & Interaction range \\
\hline Chemical adsorption & covalent & short range \\
& hydrogen bond & short range \\
Electrostatic & ion-ion & $1 / r$ \\
adsorption & ion-dipole & $1 / r^{2}$ \\
& dipole-dipole & $1 / r^{3}$ \\
Physical adsorption & dipole-induced dipole & $1 / r^{6}$ \\
& instantaneous dipole- & $1 / r^{6}$ \\
\hline
\end{tabular}

$r$ is the distance between ions or dipoles.

(2) Factors affecting sorption. All the factors related to the structure and gradient of sorbate and sorbent, as well as the interaction of sorbate and sorbent, will affect the types and kinetics of adsorption. These factors are chemical gradients of sorbate and sorbent, ionic strength, relative humidity and temperature. They directly or indirectly affect the process of adsorption through steric effects and electronic effects ${ }^{116,23-281}$.

Important properties of surface characteristics refer to the specific surface area, number of reactive surface groups, acid-base properties of the surface groups and surface charge ${ }^{[16]}$. An inverse relationship between particle size and sorption has been observed, but correlations are poor. It may be attributed to the fact that a smaller particle has a higher organic carbon content ${ }^{[22]}$.

Structural characteristics include pore-solids ratio and polymolecularity. For example, according to polymer theory, polymers are characterized on the basis of their internal structures as either the glassy or the rubbery state. The glassy state is more condensed than the rubbery state. Sorption of gases and organic molecules to the rubbery state occurs by dissolution while sorption to the glassy state occurs by hole-filling mechanism. As the temperature is higher than the glass transition temperature, polymers will converse from the glassy state to the rubbery state. And in this process, there is a gradual elimination of holes accompanied by a shift to a pure dissolution mechanism $^{[28]}$. The adsorption of HOCs reveals linear sorption isotherm for the rubbery form of polymer while it shows increasingly nonlinear sorption for the glassy state. Competition sorption occurs in glassy polymers but rubbery polymers show no competition ${ }^{[23]}$. Structurally similar molecules appear to compete more strongly ${ }^{[28]}$. For another example, sorbate structure is shown to have a minimal impact on the nature of sorption for the nonionic low-polarity compounds with relatively simple structures and for the inorganic compounds in neutral form. By contrast, sorbate structure appears to have a significant impact on compounds with complex structures. The shape of the diffusing molecules has an impact on their diffusion in polymers and it appears to be responsible for the rate-limited sorption. The addition of functional groups to a molecule such as benzene results in an increased effect of steric hindrance, which will constrain diffusion ${ }^{[29]}$.

Chemical gradients of sorbent, such as organic-carbon content, will also significantly affect sorption behavior. For sorbent with organic carbon content greater than $0.1 \%$, a highly significant correlation was found between the $K_{\mathrm{P}}$ of the compounds and the organic-carbon contents of the sorbent. Small $K_{\mathrm{P}}$ values have been found for organic-poor sorbent, even for those with a high specific surface area ${ }^{[30]}$.

$\mathrm{pH}$ can have a significant effect on nonequilibrium sorption of ionogenic HOCs while it has a negligible impact on the sorption of nonionic HOCs ${ }^{[29]}$.

An organic cosolvent also has a significant impact on adsorption of HOCs. Sorption rate constant increases with the increase of volume fraction of organic cosolvent. Organic matter in sorbent is shown to be a flexible, cross-linked and polyelectrolytic polymer. The permeation of small molecules through polymers is a function of several factors, including the size and shape of the sorbent as well as the nature and conformation of the polymer. The mechanism responsible for the impact of cosolvent on sorption kinetics is postulated to involve changes in con- 
formation of the organic matter matrix, which are induced by changes in solvent polarity that result from the addition of a cosolvent ${ }^{[31]}$.

The process of sorption will be affected by solvent, which generally depends on the quite similarity between the solvent and solute ${ }^{[19,29]}$. Polar sorbate will adsorb more polar gradients in an unpolar solution and an unpolar sorbate will adsorb unpolar sorbent in a polar solution.

The temperature may potentially affect the sorption rate in two ways in terms of intraparticle diffusion. First, diffusivities in solution and pore water vary directly with temperature. Second, temperature can change the partition coefficients and consequently change the effective diffusivities which in turn determine the sorption rates ${ }^{[26]}$.

Even if a litter amount of surfactant exists in water, the amount of sorption of organic pollutants will increase significantly. When the concentration of surfactant is higher than CMC (critical micella concentration), competition will happen between solution and desorption. The amount of sorption will decrease. Some researchers found that there is no significant difference between the impacts caused by cationic and nonionic surfactants ${ }^{[32]}$.

(3) Sorption equilibria and equilibrium models. Sorption is related to issues of classical chemistry and energy balances. At equlibrium, there is no driving force for further net chemical change and chemical potentials of a solute must be equal in the solvent and sorbate phases, from which some thermodynamics constants can be calculated.

In a given system, the amount of sorption in equilibrium is related to the temperature and the amount of solute in the solvent phase ${ }^{[33]}$. A plot of the variation of solid-phase concentration, the amount of the compound sorbed per unit mass of solid, vs. the solution phase concentration under equilibrium conditions is termed isotherm. Although several models have been proposed, each has its own assumption. By now, no model is found suitable for all systems. Linear model, Langmuire model, Freundelich model and IAST model can be widely used to describe the sorption equilibria ${ }^{[22,34,35]}$.

(4) Kinetic reaction rate models. The degree of sorption is decided by thermodynamics of sorption while its rate is decided by kinetics. Several kinetic reaction rate models are listed in table $2^{[26,29]}$.

Table 2 Kinetic reaction rate models

\begin{tabular}{ccl}
\hline Model & Equation of model & \multicolumn{1}{c}{ Appraisal } \\
\hline One-site & $\frac{\mathrm{d} S}{\mathrm{~d} t}=k_{f} C-k_{b} S$ & $\begin{array}{l}\text { not suitable for com- } \\
\text { plex systems }\end{array}$ \\
Two-site & $\frac{\mathrm{d} S_{2}}{\mathrm{~d} t}=k_{1} S_{1}-k_{2} S_{2}$ & $\begin{array}{l}\text { widely used, para- } \\
\text { meters are } k_{1} \text { and } k_{2}\end{array}$ \\
$\begin{array}{c}\text { Distributed } \\
\text { reaction }\end{array}$ & $\frac{\partial S(r)}{\partial t}=D_{\text {eff }}\left[\frac{\partial^{2}(S r)}{\partial r^{2}}+\frac{2}{r} \frac{\partial S(r)}{\partial r}\right]$ & $\begin{array}{l}\text { widely used, para- } \\
\text { meter is } D_{\text {eff }}\end{array}$ \\
\hline
\end{tabular}

While all theoretical models assume a condition of dynamic equilibrium and complete reversibility, the ki- netics of desorption, however, are generally slow and appear to be related somewhat to the age of the sorbed compound $^{[22]}$. In order to understand better the process of sorption, the energy change in the process is illustrated in fig. $1^{[36]}$.

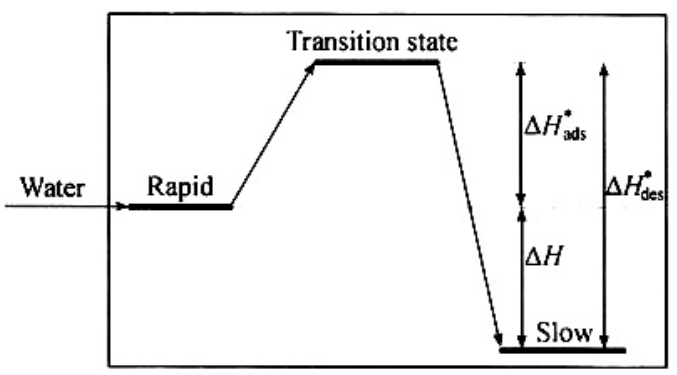

Fig. 1. The energy change in the process of sorption/desorption.

Short-term sorption enthalpies are equal to zero approximately. $\Delta H$ represents the difference between the rapid and the slow sediment compartments. $\Delta H_{\text {ads }}^{*}$ and $\Delta H_{\text {des }}^{*}$ represent the activation enthalpies of slow adsorption and desorption respectively. The relationship between the activation enthalpy for slow desorption and the rate constant $k_{\text {slow }}$ meet the Arrhenius relationship.

(iii) Sorption of PCBs in environmental media

(1) Two problems important in the process. i) Normalized partition coefficient and octanol-water partition coefficient. There is a tight relationship between octanol-water partition coefficient and the sorption coefficient of PCBs on soils, and bioaccumulation factor of $\mathrm{PCBs}^{[19]}$ as well. $K_{\mathrm{OW}}$ can be calculated from the linear free energy relationship ${ }^{[22]}$. In literature, $K_{\text {OW }}$ for a given compound frequently varies over several orders of magnitude ${ }^{[37]}$. In addition, the estimation of partition coefficient of some compound is not accurate by octanol which is the surrogate of humus. Humus can adsorb much more water than octanol, which can only solve $5 \%$ water $^{[38]}$. The polarity of humus is higher than that of octanol. It is more unfavorable for the sorption of HOCs. Natural sorbents are relative to their matrix. Their molecular size and structures are different. The interaction between octanol and HOCs is different from that between natural sorbent and octanol ${ }^{[17]}$.

$K_{\mathrm{OC}}$ is related to many physical constants, such as $K_{\text {OW }}$ and the water solubility $S^{[39]}$ :

$$
\lg K_{\mathrm{OC}}=a \lg K_{\mathrm{OW}}+b, \quad \lg K_{\mathrm{OC}}=4.04-0.557 \lg S .
$$

$K_{\mathrm{OC}}$ can be estimated by theory or experience, which includes $K_{\mathrm{OW}}, S$, and molecular connectivity ${ }^{[40.41]}$. Experimental determinations of $K_{\mathrm{OW}}$ and $S$ are time consuming. However, the partition behavior of an organic solute between the reverse phase stationary phase and the mobile phase in a high performance reverse phase liquid chromatography (HPRPLC) system is analogous to that involved in soil/sediment sorptive processes, and therefore 
it is potentially a more accurate predictor of sorption than either aqueous solubility or octanol/water partition coefficients $^{[40]}$. Quantitative structure-activity relationships (QSARs) have been proposed as a method to examine the effect of solute size and shape on sorption equlibria and sorption kinetics. Piatt ${ }^{[43]}$ reported that the QSAR approach outerperformed the conventional experimentally derived linear free energy relationship (LFER) equations and thus provided better correlations of the first-order molecular connectivity index with equilibrium sorption coefficients $^{[4] !}$.

ii ) Colloid in the environment. Colloids exist in the environment ubiquitously. They play an important role in the atmosphere, aquatic environment, soil and sediment. The diameter of colloid is in the range of $0.001-1 \mu \mathrm{m}$. It is defined as $0.001-0.45 \mu \mathrm{m}$ in sediment ${ }^{[42]}$. Because of the big specific surface area, $K_{\mathrm{OC}}$ related to colloid particles is much larger than that related to soil/sediment. The apparent solubility of organic pollutants, such as PCBs, will be enhanced if colloids exist in aqueous phase. Its apparent affinity for binding to sediment particles will be reduced $^{[37]}$. Hence failure to account for this mode of transport can lead to serious underestimates of the distances for which the contaminants will migrate ${ }^{[43]}$.

When we research the sorption mechanism of PCBs, colloids could not be omitted. A hot dispute on the sorption mechanism of PCBs is related to colloids. Sorption is an old phenomenon, many researchers had studied it in the field of classical physical chemistry. Nevertheless, it is not until recent $20-30$ years that sorption phenomena were further discussed in environmental science. In 1979, Chiou published his paper entitled A Physical Concept of Soil Water Equlibria for Nonionic Organic Compounds in Science ${ }^{[44]}$. In that paper, he proposed that the transfer of HOCs from water to soil might be described in terms of a hypothesis of solute partition in the soil organic matter and the isotherm is linear. After that, Weber and other researchers published a series of papers in Water Research in $1983^{[45.46]}$. They widened the concept proposed by Chiou and spread it from soil to aquatic environment. In this period, many researchers did plenty of related experiments in laboratory and field and lots of data obtained support the theory ${ }^{[45-48]}$.

Almost at the same time, Zabawa noticed the complexity of environmental colloids but did not use it in sorption phenomena ${ }^{[49]}$. After that, because many experimental data could not match the theory of linear sorption, scientists changed their attention from macroscopic sorption phenomena to microscopic studies which emphasized the structure and gradient of sorbate and sorbent ${ }^{[15]}$. Weber proposed the two-site mode ${ }^{[50]}$.

With the development of science and technology, especially the improvement of separation and analytical methods, scientists re-emphasize the theory proposed by Chiou after they improved the experimental condition and re-examined the phenomena of sorption. Gschwend thought that the nonlinearity of isotherm was caused by the incomplete separation of solid particles and water ${ }^{[51]}$, which is the so-called solid effect. Because of the exisence of colloid particles, the apparent solubility of organic pollutant increased and the apparent sorption isotherm became nonlinear. If the effect was revised, the sorption isotherm was still linear.

The organic carbon content and the microstructure of particles will affect the sorption behavior of HOCs. If the organic carbon content in soil is high, partition mechanism will function mainly and if the organic carbon content in soil is low, the microstructure of particles will function mainly.

(2) Sorption phenomena of PCBs in environmental media. i) Sorption/desorption of PCBs in the atmosphere. The sorption of PCBs from vapor phase to solid surface affects the transport process in and between environmental media, such as the partition of PCBs between vapor phase and aerosol or particle ${ }^{[16]}$. Sorption process also affects the volatilization of PCBs from soil ${ }^{[8,52,53]}$. In the partition process of PCBs between soil and atmosphere, soil produces a cushioning effect. When the concentration of PCBs in the atmosphere increases, soil will absorb them and when the concentration of PCBs in the atmosphere decreases, soil will release them back to the $\operatorname{atmosphere}^{[54]}$.

Partitioning of PCBs between the gas phase and aerosols has an impact on their transport mechanism and residence time. Mono- and non-ortho-substituted PCBs are sorbed to urban aerosols to a greater extent than multi-ortho congeners of the same homology. This is originated from their vapor pressures ${ }^{[5,56]}$. Mono- and non-ortho-PCBs have lower liquid phase vapor pressures and particle/gas partition coefficients were inversely related to them ${ }^{[55,56]}$. Relative humidity has no significant impact on the sorption of PCBs on aerosol. A multiple linear regression model using $\log P_{1}^{\circ}$ and the dihedral angle between the biphenyl rings explained much of the variance in sorption ${ }^{[56]}$. The amount of absorbed PCBs is proportional to the organic carbon content of the aerosol. However, some researchers proposed that the partition coefficients of PCBs were weakly related to their hydrophobicity no matter whether they were adsorbed on big or small particles ${ }^{[57]}$. This can be attributed to the non-exchangeable fractions of PCBs within the atmospheric particles. The removal of particles from the atmosphere by precipitation has been shown to be a function of particle size. Submicron scavenging contributes substantially to the overall wet removal of HOCs from the atmosphere $^{[58]}$. Aqueous PCBs concentrations in rain, predicted from ambient gaseous concentrations and Henry's law, are less than the measured filtrate concentrations, indicating that the rain is apparently supersaturated with respect to the ambient air concentrations. It 
seems that rain has an enrichment effect on PCBs. Electron micrographs indicate that the sorption of PCBs on microparticles is a main way by which PCBs remove from vapor phase. Partition coefficients suggest that atmospheric particles are more sorptive than solids in surface waters. Precipitation scavenging of particle-associated PCBs is the dominant mechanism for PCBs removal from the atmosphere despite a low ambient aerosol fraction in the atmosphere ${ }^{[57,58]}$.

ii) Sorption behavior of PCBs in soil. Soil and sediment have a structure of heterogeneity composed of organic and inorganic materials. The heterogeneity has an impact on the linearity of the isotherm and the sorption mechanism.

Soil particles can be divided into three domains to the scale of microstructure: first, the exposed inorganic mineral, which has little impact on the sorption of HOCs; second, the amorphous organic material, which is proved by the behavior of humic and fulvic acids in aquatic environment; third, the condensed organic material, the existence of which is proved by X-ray diffraction spectra ${ }^{[41]}$. Sorption of HOCs by condensed soil organic matter (SOM) appears to be energetically more favorable and more nonlinear than that by amorphous SOM, most likely because of the more heterogeneous composition and less polar character of condensed organic materials ${ }^{[25,39,44]}$. The changes in the composition of organic matter result in a decrease or increase of the relative amounts of oxygen-containing functional groups. High amounts of oxygen containing functional groups may result in an increase in the polarity of organic polymers composed of natural organic matter, and thus in a lower affinity for nonionic compounds, and thereby decreasing the sorption capacity. Therefore a relationship exists between the elemental composition and the partition coefficient.

The distributed reactivity model was proposed just based on the microscopic heterogeneity. The sorption process of HOCs on soil forms continuous or non-continuous spectrum and the sorption mechanisms on soil particles are different from adsorption to absorption. Two features of these isotherms are noteworthy in the context of distributed reactivity: first, the sorption capacities for each solute vary widely with respect to the different soils; second, the data and corresponding model features are both characteristics of heterogeneous sorbents ${ }^{[60,61]}$. We can conclude from the distributed reaction model that if each component element of sorption is governed by a nonlinear relationship between the solute and the sorbed phase, the composite isotherm will deviate from linearity $^{[28,61,62]}$. Because of the heterogeneity and multicomponent, HOCs such as PCBs will be sorbed most favorably by those regions or components of the soil which have the strongest affinity for those compounds. As those high-affinity regions become saturated, sorption of the $\mathrm{HOC}$ is limited to the less strong sorbing region ${ }^{[63]}$.
Organic carbon content and particle size have a significant impact on the sorption of $\mathrm{PCBs}^{[64]}$. Poinke and Chesters ${ }^{[65]}$ found that the sorption mechanisms of HOCs were apparently different between coarse particles and fine particles. A bell-shaped curve showing the dependence of $K_{\mathrm{OC}}$ on particle size is apparent ${ }^{[64]}$. The sorption of PCBs on soils is an adsorption process. The sorption coefficient is inversely proportional to their solubility. When Aroclors transport into the soil, they will be separated by soil like the effect of chromatography and they have a poor mobility ${ }^{166,63]}$. The distributed coefficient changes with time ${ }^{[67]}$. Different kinds of soil have different abilities to adsorb PCBs. Haque studied the sorption behavior of PCBs on different kinds of soil with $56 \mu \mathrm{g} / \mathrm{L}$ Aroclor 1254 solution. The results showed that delmonte and silicon gel do not adsorb any PCBs and the amount of adsorbed PCBs decreases in sequence as follows: woodburn, illite, montmorillonite, Kadinit ${ }^{[68]}$.

There are two steps in the process of desorption of PCBs from soil. Desorption rate of low-chlorinated PCBs is higher than that of high-chlorinated $\mathrm{PCBs}{ }^{[69]}$.

iii) Sorption behavior of PCBs in aquatic environment. Natural aquatic environment is a complex system. Besides biocomponents, it includes water, sediments, suspended solids, colloids and macromolecules.

Particles in aquatic environment are heterogeneous mixtures composed of bio- or non-bio-originated materials. Because of their small size, some of them will suspend in water for a long time ${ }^{170]}$. They have an important effect on the fate and transformation of HOCs. PCBs will be mainly concentrated on suspended particles after they go into the aquatic environment through atmospheric deposition, effluence of industrial wastewater and surface runoff. The concentration of PCBs in suspended particles is $4-10$ times higher than that in the sediment ${ }^{[71 ; 22]}$, which means that the suspended particles are the main medium on which the PCBs transport in water. Partition coefficient values are remarkably constant with relatively little dependence on the collection methodologies or the properties of the compounds. The degree of sorption of $\mathrm{PCBs}$ in water system is relative to the organic carbon content of suspended particles ${ }^{70]}$. Because of the relationship between organic carbon and the depth of the water, the concentration of PCBs is relative to the depth of the water ${ }^{[70]}$. It is also reported that the degree of sorption of PCBs is reversely relative to the particle size ${ }^{[54,68]}$. In a water system the number of coarse particles is fewer than that of fine particles. However, because of the greater mass of coarse particles, they will sedimentate much easier than fine particles and have more impact on the transport of PCBs into the sediments ${ }^{[71]}$. With the application of pesticides and the agricultural utilization of sewage, amounts large of surfactant effluents into the aquatic environment ${ }^{[32]}$. Surfactant may increase the organic carbon content of aquifer materials ${ }^{[72-74]}$. If the surfactant con- 
centrations are above critical micella concentration (CMC), solubilization and adsorption compete for the pollutant molecules, and the competition leads to a significant decrease in PCBs adsorption ${ }^{[32]}$.

Partition coefficient of PCBs between water and suspended particles is impacted by solid effects. That is to say, the partition coefficients decreases as the concentration of solids increases. However, these phenomena are contrary to the basic theory of thermodynamics ${ }^{[21]}$. According to the thermodynamics theory, in equilibrium, partition coefficient is not relative to the mass or volume of the two phases. In order to explain this phenomena the "three phases" model was proposed ${ }^{[34]}$. The theory suggests that equilibrium environmental specialty of HOCs should include three phases: the dissolved, the sorbed to non-setting particles or macromolecules and the sorbed to setting solid. With the increase of total suspended solids (TSS), colloid particles increase. Because of the inter- or intra-actions of particles, organic pollutants desorbed, which should have been easily adsorbed. It also impacts the kinetics of sorption by enhancing their diffusion path. Other scientists believe that the solid effect comes from the ineffective separation of solid phase from water phase ${ }^{[34,70]}$. After prewashing of fine particles, the linear model is fit for the environmental process. The partition coefficient is constant in a large range of sorbate concentrations ${ }^{[18.21]}$

Particle size is a significant factor that impacts the sorption behavior of PCBs. PCBs are mainly concentrated on small particles, and high chlorinated PCBs are mainly concentrated on fine particles $(\phi<63 \mu \mathrm{m})$, while low chlorinated PCBs are mainly concentrated on coarse particles $(\phi>63 \mu \mathrm{m})^{[751}$. Colloids have shown a significant effect on the sorption behavior of PCBs. In interstitial waters, $40 \%-80 \%$ of PCBs are colloidally bound. With the decrease of PCB solubility and the increase of PCB chlorination, the magnitude of $\mathrm{PCB}$-colloid interactions increases. Because of the presence of colloids, PCBs are often found in interstitial waters at concentrations exceeding their solubility. The interaction affects their bioavailability and increases their solubility and mobility $^{[76]}$. As core depth increases, the magnitude of PCB-colloid interactions also increases. This will affect their distribution in the sediment ${ }^{[77]}$. Temperature can also affect the transport of PCBs from sediment to water body, The rate of transport in summer is faster than that in win$\operatorname{ter}^{[19]}$.

Some researches have proved that the mechanism of PCBs sorption on sediment is partition, the non-linearity of isotherm is caused by the solid effect ${ }^{[17,78]}$. Controversially, some researchers believe that it is caused by slow sorption kinetics and steric hindrance ${ }^{[76]}$. Our research work supports the linear sorption of Aroclor 1242 (fig. 2) while Weber's work supports the same mechanism of Aroclor 1254 (table 3).

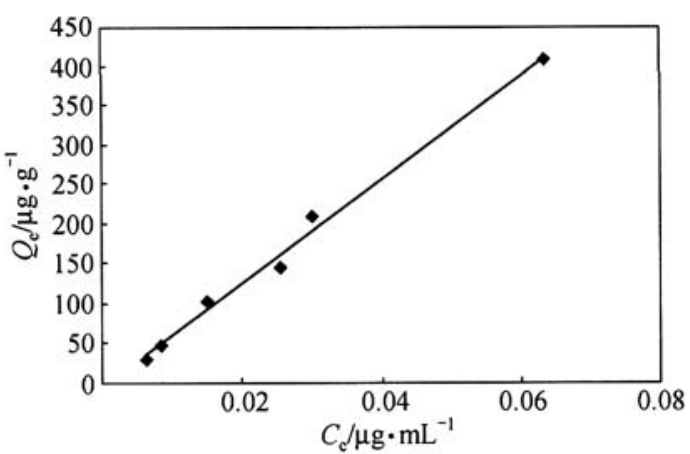

Fig. 2. Sorption isoterm of Aroclor 1242 at $25^{\circ} \mathrm{C} . y=6585.9 x-7.4739$, $R^{2}=0.9925$.

As PCBs' input into natural waters decreases, their future aqueous concentrations may be increasingly controlled by sediment-water interaction ${ }^{[79]}$. Sorption and condensation process in sediments play an important role in the removal of PCBs from aquatic system. However, when the condition changes, sediment may be the source of PCBs, that is a "chemical time bomb". Some researches show that sorption of PCBs by the sediments can only remove a small part of them. Most of them recycle into the environment. Desorption process of PCBs includes two steps. A slow process follows a rapid one. The rate of slow desorption becomes faster with the increase of temperature ${ }^{[36,80]}$. This can be attributed to the different diffusion rates of PCBs in amorphous or condensed natural polymers $^{[80]}$.

Table 3 Parameters of the sorption of Aroclor 1254

\begin{tabular}{ccccc}
\hline Sorbate & $\mathrm{OC}(\%)$ & $K_{\mathrm{p}}$ & $C_{\mathrm{o}} / \mu \mathrm{g} \cdot \mathrm{m}^{-3}$ & Coefficient \\
\hline Sediment 1 & 3.45 & 23.760 & 9.6 & 0.999 \\
Sediment 2 & 9.48 & 88.981 & 8.2 & 0.920 \\
\hline
\end{tabular}

OC, Organic carbon; $K_{\mathrm{p}}$, partition coefficient; $C_{\mathrm{e}}$, concentration of PCBs in aqueous phase.

\section{Conclusion and prospect}

It is the sorption/desorption process that impacts other environmental behavior. In this field, many theories and models have been proposed. However, none of them can be used under all circumstances. So it is important to study the sorption mechanism of PCBs, which will give scientists effective scientific support to the study of the fate of POPs in the environment and the risk assessment and management of PCBs.

Acknowledgements This work was supported by the Knowledge Innovation Program of the Chinese Academy of Sciences (Grant No. RCEES9906), the Bureau of Resource and Environment of the CAS (Grant No. KZ951-B-1-209-02) and the National Natural Science Foundation of China (Grant No. 29837180).

\section{References}

1. Dai, S. G., Yue, G. C., Wang, X. R. et al., Environmental Chemistry (in Chinese), Beijing: Higher Education Press, 1997, 269275.

2. Wang, L. S., Organic Pollutant Chemistry (II) (in Chinese), Beijing: Science Press, 1991, 233-244.

3. Shiu, W. Y., Mackay, D., A critical review of solubilities, vapor 
pressures, Henry's law constants, and octanol-water partition coefficients of the polychlorinated biphenyl, J. Phys. Chem. Ref. Data, 1986, 15(2): 911.

4. World Health Organization, Polychlorinated Biphenyls and Terphenyls (in Chinese), Beijing: Chinese Environmental Science Publishing House, 1979, 3-65.

5. World Health Organization, Polychlorinated Biphenyls and Terphenyls (2nd ed.), Geneva: WHO, 1993, 92-98.

6. Kannan, K., Nakata, H., Stafford, R. et al., Bioaccumulation and toxic potential of extremely hydrophobic polychlorinated biphenyl congeners in biota collected at a superfund site contaminated with Aroclor 1268, Environ. Sci. Technol., 1998, 32(9): 1214.

7. Kim, Y., Cooper, K. R., Interactions of 2,3,7,8-tetrachlorodibenzo-p-dioxin (TCDD) and 3,3'4,4',5-pentachlorobiphenyl (PCB 126) for producing lethal and sublethal effects in the Japanese medaka embryos and larvae, Chemosphere, 1998, 36(2): 409.

8. Hu, Y. M., Wang, M. J., Methodology for studying the fate and mobility of organic pollutants in soil, Advances in Environmental Science (in Chinese), 1998, 6(4): 44.

9. Keith, L. H., Telliard, W. A., Priority pollutants ( I ) - a perspective view, Environ. Sci. Technol., 1979, 13(4): 416.

10. Matsumura, T., Tsubota, H., Ikeda, Y. et al., Retention order of all 209 chlorobiphenyl compounds on capillary column SGEHT8, Organohalogen Compd., 1997, 21: 14.

11. Alvarado, J. S., Silzer, J., Lemley, F. et al., Separation of PCBs by fast gas chromatography, Anal. Commun., 1997, 34(12): 381.

12. Diaz, F. J., Rodriguez, L. M. C., Comellas, L. et al., Bioanalytic methods applied to endocrine disrupting polychlorinated biphenyls, polychlorinated dibenzo-p-dioxins and polychlorinated dibenzofurans, TrAc, 1997, 16(10): 563.

13. Yang, Y., Hawthorne, S. B., Miller, D. J. et al., Adsorption versus absorption of polychlorinated biphenyls onto solid-phase microextraction coatings, Anal. Chem., 1998, 70(9): 1866.

14. Chu, S. G., Xu, X. B., Tong, Y. P., Transport and distribution of polychlorinated biphenyls in a polluted area, Acta Scientiae Circumstantiae (in Chinese), 1995, 15(4): 423.

15. Weber, W. J. Jr., McGinley, P. M., Katz, L. E., Sorption phenomena in subsurface systems: concepts, models and effects on contaminant fate and transport, Wat. Res., 1991, 25(5): 499.

16. Sigg, L., Goss, K. U., Haderlein, S. et al., Sorption phenomena at environmental solid surfaces, Chimia, 1997, 51(12): 893.

17. Chin, Y. P., Weber, W. J. Jr., Estimating the effects of dispersed organic polymers on the sorption of contaminants by natural solids: 1. A predictive thermodynamic humic substance-organic solute interaction model, Environ. Sci. Technol., 1989, 23(8): 978.

18. Bergen, B. J., Nelson, W. G., Pruell, R. J., Partitioning of polychlorinated biphenyl congeners in the seawater of new Bedford harbor, Massachusetts, Environ. Sci. Technol., 1993, 27(5): 938.

19. Ye, C. M., Environmental Pollution in Multi-media (in Chinese), Beijing: Science Press, 1997, 60-63.

20. Zhan, W., Wu, W. Z., Xu, Y. et al,, Prospective of adsorption/desorption of xenobiotics in soil/sediment system, Advances in Environmental Science (in Chinese), 1998, 6(3): 1.

21. Voice, T. C., Rice, C. P., Weber, W. J, Jr., Effect of solids concentration on the sorptive partitioning of hydrophobic pollutants in aquatic systems, Environ. Sci. Technol., 1983, 17(9): 513.

22. Voice, T. C., Weber, W. J. Jr., Sorption of hydrophobic compounds by sediments, soils and suspended solids (I) - Theory and background, Wat. Res., 1983, 17(10): 1433.

23. Young, T. M., Weber, W. J, Jr., A distributed reactivity model for sorption by soils and sediments: 3 . Effects of diagenetic processes on sorption energetics, Environ. Sci. Technol., 1995, 29(1): 92.
24. Piatt, J. J., Backhus, D. A., Capel, P. D. et al., Temperature-dependent sorption of naphthalene, phenanthrene, and pyrene to low organic carbon aquifer sediments, Environ. Sci. Technol., 1996, 30(3): 751 .

25. Weber, W. J. Jr., Huang, W., A distributed reactivity model for sorption by soils and sediments: 4 . Intraparticle heterogeneity and phase-distribution relationships under nonequilibrium conditions, Environ. Sci. Technol., 1996, 30(3): 881.

26. Wu, S. C., Gschwend, P. M., Sorption kinetics of hydrophobic organic compounds to natural sediments and soils, Environ. Sci. Technol., 1986, 20(7): 717.

27. Cameron, D. R., Klute, A., Convective-dispersive solute transport with a combined equilibrium and kinetic adsorption model, Wat. Res. Res., 1977, 13(1): 183.

28. Xing, B., Pignatello, J. J., Dual-mode sorption of low-polarity compounds in glassy polymer (vinyl chloride) and soil organic matter, Environ. Sci. Technol., 1997, 31(3): 792.

29. Brusseau, M. L., Rao, P. S. C., Influence of sorbate structure on nonequilibrium sorption of organic compounds, Environ. Sci. Technol., 1991, 25(8): 1501.

30. Schwarzenbach, R. P., Westall, J., Transport of nonpolar organic compounds from surface water to groundwater-laboratory sorption studies, Environ. Sci. Technol., 1981, 15(11): 1360.

31. Brussear, M. L., Wood, A. L., Rao, P. S. C., Influence of organic cosolvents on the sorption kinetics of hydrophobic organic chemicals, Environ. Sci. Technol., 1991, 25(5): 903.

32. Rheinländer, T., Klumpp, E., Schwuger, M. J., On the adsorption of hydrophobic pollutants on surfactant/clay complexes: comparison of the influence of a cationic and a nonionic surfactant, J. Dispersion Science and Technology, 1998, 19(2): 379.

33. Fu, X. C., Shen, W. X., Yao, T. Y., Physical Chemistry (II) (in Chinese), Beijing: Higher Education Press, 1990, 934-964.

34. Gschwend, P. M., Wu, S. C., On the constancy of sediment-water partition coefficients of hydrophobic organic pollutants, Environ. Sci. Technol., 1985, 19(1): 90.

35. Karickhoff, S. W., Semi-empirical estimation of sorption of hydrophobic pollutants on natural sediments and soils, Chemosphere, 1981, 10(8): 833.

36. Cornelissen, G., Noort, P. C. M. V., Parsons, J. R. et al., Temperature dependence of slow adsorption and desorption kinetics of organic compounds in sediments, Environ. Sci. Technol., 1997, 31(2): 454.

37. Karickhoff, S. W., Brown, D. S., Scott, T. A., Sorption of hydrophobic pollutants on natural sediments, Wat. Res., 1979, 13(3): 241.

38. Chiou, C. T., Schmedding, D. W., Partitioning of organic compounds in octanol-water systems, Environ. Sci. Technol., 1982, $16(1): 4$.

39. Grathwohl, P., Influence of organic matter from soils and sediments from various origins on the sorption of some chlorinated aliphatic hydrocarbons: implications on $K_{\mathrm{OC}}$ correlations, Environ. Sci. Technol., 1982, 24(11): 1687.

40. Chin, Y. P., Peven, C. S., Weber, W. J. Jr., Estimating soil/sediment partition coefficients for organic compounds by high performance reverse phase liquid chromatography, Wat. Res., 1988, 22(7): 873 .

41. Piatt, J. J., Brusseau, M. L., Rate-limited sorption of hydrophobic organic compounds by soils with well-characterized organic matter, Environ. Sci. Technol., 1998, 32(11): 1604.

42. Valsaraj, K. T., Verma, S., Sojitra, I. et al., Diffusive transport of organic colloids from sediment beds, J. of Environmental Engineering, 1996, 8: 722 . 
43. McCarthy, J. F., Zachara, J. M., Subsurface transport of contaminants, Environ. Sci. Technol., 1989, 23(5): 496.

44. Chiou, C. T., Peters, L. J., Freed, Z. H., A physical concept of soil-water equilibria for nonionic organic compounds, Science, 1979, 206(16): 831 .

45. Voice, T., Weber, W. J. Jr., Sorption of hydrophobic compounds by sediments, soils and suspended solids (I ) - Theory and background, Water. Res., 1983, 17: 1433.

46. Weber, W. J. Jr., Voice, T. C., Pirbazari, M. et al., Sorption of hydrophobic compounds by sediment, soils and suspended solids (II) - Sorbent evaluation studies, Water Res., 1983, 17: 1443.

47. Voice, T. C., Rice, C. P., Weber, W. J. Jr., Effect of solids concentration on the sorptive partitioning of hydrophobic pollutants in aquatic systems, Environ. Sci. Technol., 1983, 17: 513.

48. Ball, W. P., Roberts, P. V., Long-term sorption of halogenated organic chemicals by aquifer material: 1 . Equilibrium, Environ. Sci. Technol., 1991, 25: 1223.

49. Zabawa, C. F., Microstructure of agglomerated suspended sediments in Northern Chespeake Bay Estuary, Science, 1978, 202: 49.

50. Pignatello, J. J., Slowly reversible sorption of aliphatic halocarbons in soils ( I ) - Formation of residual fractions, Environ. Toxicol. Chem., 1990, 9: 1107.

51. Gschwend, P. M., Wu, S., On the constancy of sediment-water partition coefficients of hydrophobic organic pollutants, Environ. Sci. Technol., 1985, 19: 90.

52. Lpoulsen, T. G., Moldrup, P., Yamaguchi, T. et al., VOC vapor sorption in soil: soil type dependent model and implications for vapor extraction, J. of Environmental Engineering, 1989, 2: 146.

53. Alcock, R. E., Johnston, A. E., McGrath, S. P. et al., Long-term changes in the polychlorinated biphenyl content of United Kingdom soils, Environ. Sci. Technol., 1993, 27(9): 1918.

54. Harner, T., Mackay, D., Jones, K. C., Model of the long-term exchange of PCBs between soil and the atmosphere in the southern UK, Environ. Sci. Technol, 1995, 29(5): 1200.

55. Cotham, W. E., Bidleman, T. F., Laboratory investigations of the partitioning of organochlorine compounds between the gas phase and atmospheric aerosols on glass fiber filters, Environ. Sci. Technol., 1992, 26: 469.

56. Falconer, R. L., Bidleman, T. F., Cotham, W. E., Preferential sorption of non- and mono-ortho-polychlorinated biphenyls to urban aerosols, Environ. Sci. Technol., 1995, 29(6): 1666.

57. Poster, D, L., Baker, J. E., Influence of submicron particles on hydrophobic organic contaminants and distributions of polycyclic aromatic hydrocarbons and polychlorinated biphenyls in rainwater, Environ. Sci. Technol., 1996, 30(1): 341.

58. Gonzales, T. W., Murr, L. E., An electron microscopy study of particulates present in individual raindrops, J. of Geophysical Research, $1977,82(21)$ : 3161 .

59. Dtinker, J. C., Bouchertall, F., On the distribution of atmospheric polychlorinated biphenyl congeners between vapor phase, aerosols, and rain, Environ. Sci. Technol., 1989, 23(1): 57.

60. Connaughton, D. F., Stedinger, J. R., Lion, L. W. et al., Description of time-varying desorption kinetics: release of naphthalene from contaminated soils, Environ. Sci. Technol., 1993, 27(12): 2397.

61. Weber, W. J. Jr., McGlnley, P. M., Katz, L. E., A distributed reactivity model for sorption by soils and sediments: 1 . Conceptual basis and equilibrium assessments, Environ. Sci. Technol., 1992, 26(10): 1955 .

62. Brusseau, M. L., Using QSAR to evaluate phenomenological models for sorption of organic compounds by soil, Environ.
Toxicol. Chem., 1993, 12: 1835.

63. McGlnley, P. M., Katz, L. E., Weber, W. J. Jr., A distributed reactivity model for sorption by soils and sediments: 2 . Multicomponent systems and competitive effects, Environ. Sci. Technol., 1993, 27(8): 1524.

64. Chiou, C. T., Porter, P. E., Schmedding, D. W., Partition equilibria of nonionic organic compounds between soil organic matter and water, Environ. Sci. Technol., 1983, 17(4): 227.

65. Pionke, H. B., Chesters, G., Pesticide-sediment water interactions, J. Envir. Quality, 1973, 2(10): 29.

66. Chu, S. G., Yang, C., Xu, X. B. et al., Polychlorinated biphenyl congener residuals in sediment and soil from pollution area, China Environmental Science (in Chinese), 1995, 15(3): 199.

67. Girvin, D. C., Scott, A. J., Polychlorinated biphenyl sorption by soils: measurement of soil-water partition coefficients at equilibrium, Chemosphere, 1997, 35(9): 2007.

68. Haque, R., Schmedding, D. W., Freed, V. H., Aqueous solubility, adsorption, and vapor behavior of polychlorinated biphenyl Aroclor 1254, Environ. Sci. Technol., 1974, 8(2): 139.

69. Ghosh, U., Weber, A. S., Jensen, J. N., Influence of PCB desorption kinetics on bioremediation and mobility risk, Hazard Ind. Wastes, 1997, 29: 404.

70. Thibodeaux, L. J., Valsaraj, K. T., Reible, D. D., Associations between polychlorinated biphenyls and suspended solids in natural waters: an evaluation of the uptake rate by particles, Wat. Sci. Technol., 1993, 28(8): 215.

71. Wu, W. Z., Schramm, K. W., Henkelmann, B. et al., PCDD/Fs, PCBs, HCHs and HCB in sediment sand soils of Ya-er Lake area in China: Results on residual levels and correlation to the organic carbon and the particle size, Chemosphere, 1997, 24(1): 191.

72. Park, J. W., Jaffé, P. R., Partitioning of three nonionic organic compounds between adsorbed surfactants, miceilea, and water, Environ. Sci. Technol., 1993, 27(12): 2559.

73. Hayworth, J. S., Burris, D. R., Nonionic surfactant-enhanced solubilization and recovery of organic contaminants from within cationic surfactant-enhanced sorbent zones (2): Numerical simulations, Environ. Sci. Technol., 1997, 31(5): 1284.

74. Hayworth, J. S., Burris, D. R., Nonionic surfactant-enhanced solubilization and recovery of organic contaminants from within cationic surfactant-enhanced sorbent zones (1): Experiments, Environ. Sci. Technol., 1997, 31(5): 1277.

75. Pierard, C., Budzinski, H., Garrigues, P., Grain-size distribution of polychlorobiphenyls in coastal sediments, Environ. Sci. Technol., 1996, 30(9): 2776.

76. Burgess, R. M., Mckinney, R, A., Brown, W. A., Enrichment of marine sediment colloids with polychlorinated biphenyls: trends resulting from $\mathrm{PCB}$ solubility and chlorination, Environ. Sci. Technol., 1996, 30(8): 2556.

77. Formica, S. J., Baron, J. A., Thibodeaux, L. J. et al., PCB transport into lake sediments: Conceptual model and laboratory simulation, Environ. Sci. Technol., 1988, 22(12): 1435.

78. Gschwend, P, M., Wu, S. C., On the constancy of sediment-water partition coefficients of hydrophobic organic pollutants, Environ. Sci. Technol., 1985, 19(1): 90.

79. Horzempa, L. M., Toro, D. M. D., The extent of reversibility of polychlorinated biphenyl adsorption, Wat. Res., 1983, 17(8): 851.

80. Carroll, K. M., Harkness, M. R., Bracco, A. A. et al., Application of a permeate/polymer diffusional model to the desorption of polychlorinated biphenyls from Hudson river sediments. Environ. Sci. Technol., 1994, 28(2): 253. 